\title{
Three-dimensional stopping sight distance control on passing lanes of divided highways
}

\author{
Stergios Mavromatis ${ }^{1} \cdot$ Fotis Mertzanis $^{2} \cdot$ Giorgos Kleioutis $^{3} \cdot$ Basil Psarianos $^{4}$
}

Received: 20 September 2014 / Accepted: 3 February 2016/Published online: 17 February 2016

(C) The Author(s) 2016. This article is published with open access at SpringerLink.com

\begin{abstract}
Introduction Stopping Sight Distance control of passing lanes of divided highways represents currently a discussion point among researchers. A 3-D approach to address the issue is accepted as the overall solution to the problem by both researchers and contemporary design policies. This paper aims to contribute to the problem by presenting a sound and practical design solution to it with an analytic and a design values based format.

Methods The solution approach consists of both a realistic description of the 3-D highway configuration and a 3-D vehicle kinematics calculation of the stopping maneuver along the vehicle's actual path. A SSD control method, previously
\end{abstract}

Stergios Mavromatis

stemavro@survey.ntua.gr

Fotis Mertzanis

fmertz@civil.ntua.gr

Giorgos Kleioutis

gkleioutis@teiath.gr

Basil Psarianos

psari@survey.ntua.gr

1 Technological Educational Institute of Athens, School of Surveying Engineering, 2 Agiou Spiridonos Str., GR-12210 Athens, Greece

2 School of Civil Engineering, National Technical University of Athens, 9 Hiroon Polytechniou Str., GR-15780 Athens, Greece

3 School of Surveying Engineering, Technological Educational Institute of Athens, 2 Agiou Spiridonos Str., GR-12210 Athens, Greece

4 School of Rural \& Surveying Engineering, National Technical University of Athens, 9 Hiroon Polytechniou Str., GR-15780 Athens, Greece developed by the authors', that relates concurrently the 3D configuration of a roadway to the kinematics of a vehicle moving along the actual roadway path, is applied, as a tool for the assessment of critical design parameters directly related to SSD adequacy.

Results A rather comfortable alignment case consisting of a left curved divided highway overlapped with crest vertical curve parameters for numerous horizontal - vertical arrangements is examined, where an extensive area of SSD inadequacy during emergency braking procedure is reported.

Conclusions The authors propose that the optimal solution to achieve SSD adequacy on left curved divided highways is to increase object height. This would preserve design consistency as well as driver expectations, by avoiding the need for lateral widening or site-specific speed limits. More specifically the object height is suggested to be equivalent to the driver's height of $1.08 \mathrm{~m}$ (AASHTO 2011). This would require additional stop lights on those vehicles whose stop lights are currently below this level. Although such a requirement regarding the current vehicle fleet is not feasible, vehicle industries as well as road design guidelines should address this issue in the near future.

Keywords Stopping Sight Distance (SSD) · 3D road alignment $\cdot$ Design consistency $\cdot$ Safety

\section{Introduction and problem statement}

In current highway design practice [1-4], the threedimensional highway geometry is still addressed by designing it in two independent and mostly uncorrelated twodimensional stages, namely, the horizontal alignment and the vertical profile. This 2-D approach while inevitable in many cases has proven to be associated with design misconceptions 
that influence the design performance adversely. For example, based on the recent German RAL (2012) rural road design guidelines [5], critical safety issues may rise in cases where crest vertical curves are designed in advance of horizontal curves due to the limited perception by the drivers of the horizontal alignment. In general, such cases of design misconceptions are experienced during the determination of the critical parameter of Stopping Sight Distance (SSD).

However, the 2-D SSD calculation is inexact, fragmentary and may produce design deficiencies due to inaccurate calculation of the available sight distance. Hassan et al. [6], for example, stated that 2-D SSD investigation might underestimate or overestimate the available sight distance and consequently lead to safety violation. Furthermore, a pure 2-D SSD design control can be detrimental to the cost or performance of a divided highway. In many cases of SSD inadequacy a usual solution is either an increase of the inner shoulder width or to a decrease of the posted speed under wet pavement conditions, the latter being a common case in Europe due to a lack of available land. Therefore contemporary highway design policies try to define 3-D design rules that assist designers efficiently and address the SSD inadequacy problem. For example, the Green Book [1] stresses that, in order for SSD provision to be granted, the vertical curve should be entirely designed inside the horizontal curve. In the Spanish Design Guidelines [4] the desired horizontal - vertical curve arrangement is reached when the vertical crest curve falls completely inside the horizontal curve including spirals. However, such provisions do not actually address all design cases and therefore a final 3-D perspective evaluation of the roadway is inevitable [2].

In recognition of the deficiencies of 2-D design approach in SSD evaluation, many researchers have started addressing the problem directly in three dimensions. One of the first researchers that assessed the available sight distance on 3-D alignment, Sanchez [7], studied the interaction between the sight distance and the 3-D combined alignment idealized into a net of triangles using Inroads software [a specific road design software, (http://www.bentley.com)]. In this research, the operator, assisted by the different views generated by the computer, was able to determine the obstruction impeding the driver's sight line. Although this methodology was accurate, it was very time consuming since the available sight distance was determined graphically (not analytically).

Several years later, Hassan et al. [8] presented an analytical model for computing available sight distance on combined horizontal and vertical highway alignments, using parametric finite elements (4, 6 and 8-node rectangular elements as well as 3-node triangular elements) to represent the highway and sight obstructions. The idea behind the proposed model is summarized in checking the driver's sight line, which is represented by a straight line between the driver's eye and an object, against all the possible sight obstructions, by using an iterative procedure.
Lovell et al. [9] developed a method to calculate the sight distance based on horizontal geometry, without considering the effect of vertical geometry. Nehate and Rys [10] described a methodology to define the available sight distance using Global Positioning System (GPS) data by examining the intersection of line of sight with the elements representing the road surface. However, the available sight distance was not based on the road's compound (horizontal and vertical) alignment.

In order to evaluate the actual sight distance in real driving conditions, a number of 3-D models can be found in the literature [11-17] which base their performance through the correlation between the road surface, the ground terrain and the roadside environment and aim at optimizing the available sight distance.

Recently, Kim and Lovell [18] delivered a 3-D sight distance evaluation method where an algorithm is used to determine the maximum available sight distance using computational geometry and thin plate spline interpolation to represent the surface of the road. The available sight distance is measured by finding the shortest line that does not intersect any obstacle.

Jha et al. [19] proposed a similar to the present paper 3-D methodology for measuring sight distance along a roadway's centerline, utilizing triangulation methods via a specific algorithm introduced for this purpose, consisting of three stages, namely road surface development, virtual field of view surface development, and virtual line of sight plane development. However, the process involved multiple software platforms, thus delivering an accurate but non-flexible outcome.

The above mentioned 3-D models are capable of simulating accurately compound road environments where an unsuccessful arrangement of vertical and horizontal alignment may exist, and therefore allow the definition of the actual vision field to the driver. However, as already stated above, most of the previously mentioned research studies are focused in optimizing the available SSD by introducing either new algorithms or design parameter combinations, ignoring in many cases the topographic visual restraints. Moreover, none of the above mentioned approaches suggested a comprehensive methodology to simulate from a 3-D perspective concurrently both the alignment design and the vehicle kinematics on the road surface during emergency braking.

The SSD adequacy investigation that follows is an accurate procedure, based on a realistic representation of the roadway features, where the ground, travel surfaces and roadside elements are all taken into account. Although the developed methodology can be assessed on any road type, the present paper is focused in investigating SSD adequacy on left curved divided highways, since as stated later in the manuscript, this alignment type is critical. In particular, the proposed procedure identifies areas of interrupted vision lines between driver and obstacle at left-turn curves due to the presence of median 
concrete barriers, where the vision line lengths may be less than the required distance necessary to bring the vehicle safely to a stop. The procedure can be implemented to new road designs and existing divided highways alike, where in addition to other investigations the impact of the object height to the SSD design control, in terms of providing possible realistic solutions based on existing design parameter selection, is addressed as well.

\section{SSD modeling proposal}

In the present paper, the SSD adequacy investigation is based on a process, recently proposed by the authors that relates the 3D configuration of a roadway to the kinematics of a vehicle moving along the actual roadway path, based on the difference between the available and the demanded SSD [20, 21]. The full mathematical background of the proposed SSD assessment is fully described in [20]. Both SSD $_{\text {DEMANDED }}$ and $\mathrm{SSD}_{\mathrm{AVAILABLE}}$ are briefly presented below.

\subsection{Calculation of SSD demanded}

According to existing design policies, the demanded SSD consists of two distance components: the distance traveled during driver's perception-reaction time to the instant the brakes are applied and the distance while braking to stop the vehicle (pure braking distance). The SSD model adopted by many Design Policies is represented by Eq. (1).

$$
S S D=V_{o} t+\frac{V_{o}^{2}}{2 g\left(\frac{a}{g}+s\right)}
$$

where :

$\mathrm{V}_{\mathrm{o}}(\mathrm{m} / \mathrm{sec}) \quad$ vehicle initial speed

$\mathrm{t}(\mathrm{sec}) \quad$ driver's perception-reaction time

(ex. $2.5 \mathrm{sec}$ [1], $2.0 \mathrm{sec}$ [2])

$\mathrm{g}\left(\mathrm{m} / \mathrm{sec}^{2}\right) \quad 9.81$ gravitational constant

a $\left(\mathrm{m} / \mathrm{sec}^{2}\right) \quad$ vehicle deceleration rate

(ex. $3.4 \mathrm{~m} / \mathrm{sec}^{2}$ [1], $3.7 \mathrm{~m} / \mathrm{sec}^{2}$ [2])

$\mathrm{s}(\% / 100)$ road grade $[(+)$ upgrades,

$$
(-) \text { downgrades] }
$$

In the $\mathrm{SSD}_{\text {DEMANDED }}$ determination, the above formula ignores curved areas of both horizontal and vertical alignment, since, on one hand, the portion of friction provided in the longitudinal direction, assigned to serve the braking process, is associated directly to the friction demanded laterally [22], and on the other, the grade values involved in vertical curves are variable. In order to incorporate the effect of these parameters, simple considerations based on the mass point model as well as the laws of mechanics were applied respectively. As a result Eq. (1) was enriched by the utilized longitudinal friction, based on the well-known friction circle [22], as well as the actual grade influence, defined by adding portions of pure braking distances extracted for time fragments (steps) of $0.01 \mathrm{sec}$, the effect of which seems to be significant in combined horizontal and crest vertical curved alignments [21].

\subsection{Calculation of Available Sight Distance (ASD)}

The ASD is described as the uninterrupted line of sight between the driver's eye and the obstacle, and depends mainly on the alignment configuration as well as the various sight obstructions due to constructional elements or equipment of the roadway (backslopes, barriers, walls, etc.).

In the present paper, in order to laterally position the driver's eye at any desired offset from the typical crosssection centerline, as well as to identify visibility levels due to the presence of these elements, the term roadlines is introduced. Roadlines are defined as lines running longitudinally across the roadway that split the road's cross section into areas of uniform or linearly varied transverse slopes. Roadlines can be defined beyond the travel area as well to include the remaining distinctive parts of a road's cross section, namely, roadside elements, cut-fill slopes and slope - ground intersection [20].

Figure 1 shows, in both plan and cross-sectional view, an example of the required roadlines in order to perform a SSD adequacy examination on the passing lane of a left curved divided road section. It can be seen (Fig. 1) that six roadlines should be defined per direction of travel, where besides the centerline:

- four roadlines define the Jersey barrier layout (lines through points 1-4)

- one roadline defines the lateral position of the driver's eye as well as the object at an axis offset equal to half of the passing lane width (line through point 5)

- one roadline (through point 6) describes the roadway edgeline

The roadline calculation step is user-specified and delivers a number $n$ of cross-sections where $n$ is defined as the total roadway length divided by a selected calculation step. It is obvious that the precision of the available SSD definition depends on the selected incremental distance (calculation step). In general, a step value of $5 \mathrm{~m}$ delivers adequate precision.

Furthermore, by connecting a point on one roadline with two relative points on an adjacent roadline, a network of triangles is created representing the roadway surface. The creation of the final roadway model is based on the triangulation of the above mentioned distinctive parts.

Equations of analytical geometry are applied at that time, in order to describe lines of sight beginning from the driver's eye 
Fig. 1 Roadline layout for SSD adequacy examination on the passing lane of a left-turn curve divided road section

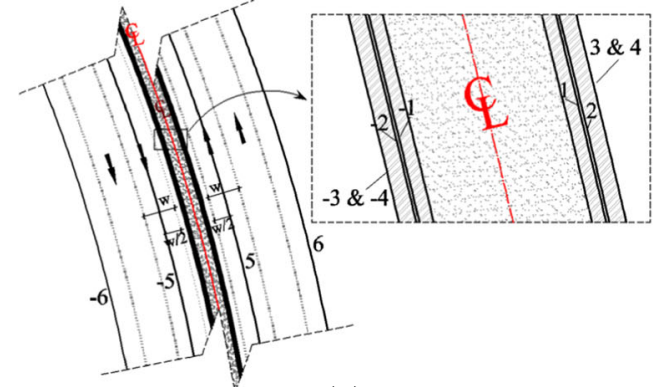

(a)

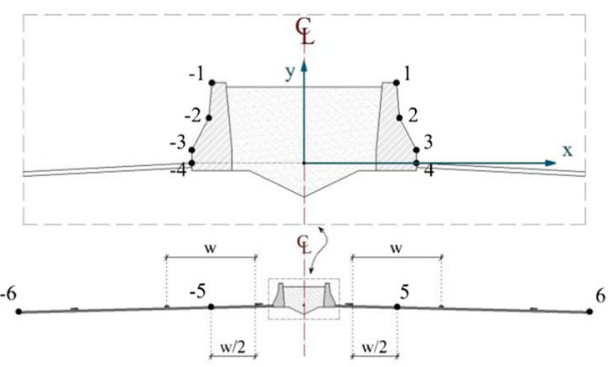

(b)

Legend: (a): plan view, (b): cross-section view,

(-) sign refers to the left roadway, w: passing lane width

and to determine their intersection points with triangles formed by the road geometry as well as features that may restrict the driver's vision towards the object [20].

\subsection{SSD adequacy}

SSD adequacy is granted when:

$$
\mathrm{SSD}_{\text {DEMANDED }} \leq \mathrm{SSD}_{\text {AVAILABLE }}
$$

The available and demanded SSD values are defined through the difference of the road stations between starting and ending points, assumed at any desired axis offset, usually equal to half of the lane width. The above process is recently incorporated in $\mathrm{H} 12$ road design software [23], used by many engineering firms in Greece for road designing, and applied for the assessment that follows.

The credibility of the road design software in defining the $\mathrm{SSD}_{\text {AVAILABLE }}$ was validated against an existing road section lacking SSD adequacy, which was surveyed via laser scanner [24]. The graphical definition of the available SSD values, using appropriate market software [25], was correlated against the relevant SSD values extracted from $\mathrm{H} 12$, where the available SSD values from the two different assessments were found to be almost identical.

\section{Median barrier design on divided highways}

Roadside barriers are placed in the longitudinal direction of high-speed roadways to redirect errant vehicles and shield them from hitting obstacles along either side of the road [1, 26]. Barriers may also be placed in the median area to prevent out-of-control vehicles in one direction from crossing to the other road direction, in which case they are called median barriers. The presence of median barriers on left-turn curved divided highways, although they increase the level of safety, under certain circumstances may affect the sight distance available to drivers [27].
The selection process of the appropriate traffic barrier type is a complicated task since many parameters are involved, where the most important goals to be served are safety, operational and economic considerations. As for providing SSD adequacy, the barrier height and the clearance between the barrier and the left edge of the passing lane, known as inner shoulder width, seems to be the most critical issues [ex. 1, 28].

Since on divided highways, in cases of potential vehicle collisions, rather shallow impact angles are expected, at least in the median areas, as well as for maintenance reasons, rigid concrete barrier types seem to be more appropriate compared to other (e.g., steel barrier) types [26]. However, in any utilized median barrier type, vehicles travelling on the opposite direction should not interrupt the driver's line of sight. Figure 2 shows a cross-section example of "New Jersey" concrete barrier type with $0.81 \mathrm{~m}$ height, as shown in Roadside Design Guide [26] and as utilized in highway design in Greece.

\section{Existing sight distance approach on left curved divided highways}

Although the necessity for SSD adequacy on left-turn curves of divided highways is emphasized in current design practice [ex. $1-3,29]$, no explicit process is provided to accurately implement this control. The only available tool in defining the available SSD is the $2 \mathrm{D}$ approach according to which $\mathrm{SSD}_{\mathrm{AVAILABLE}}$ is defined by the lateral clearance and the curve radius. However this consideration applies only to circular curves longer than the sight distance where both driver and obstacle are positioned on the circular curve [1]. Moreover, between the driver height and the obstacle height, there is no assurance whether the barrier height and/or the presence of a vertical curve does not obstruct the driver's line of sight.

SSD adequacy in current practice is once again defined by subtracting $\mathrm{SSD}_{\text {AVAILABLE }}$ from $\operatorname{SSD}_{\text {DEMANDED }}$ (Eq. 2) where two different options exist:

- for a given road geometry (horizontal, vertical, typical cross-section) of a divided highway section to determine 


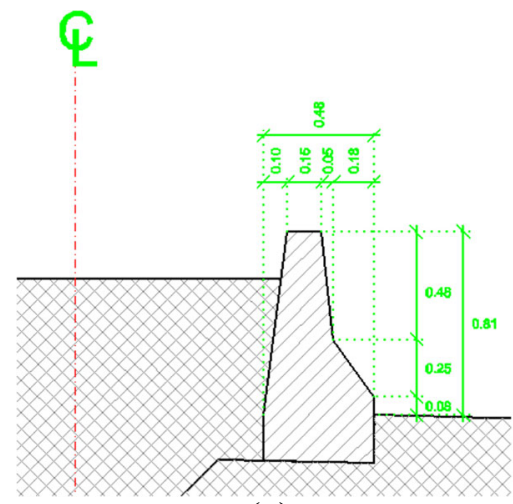

(a)

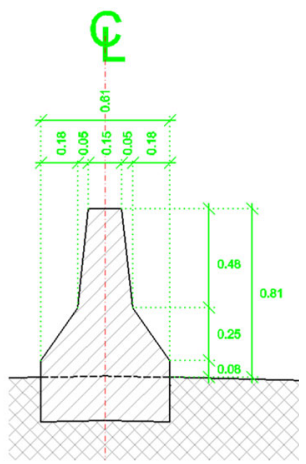

(b)
NOTE: (a: single sided, b: double sided).

Fig. 2 Example dimensions of "New Jersey" concrete median barrier type

the safe speed of the examined curve to serve as a posted speed value;

- for desired speed value on the curved road geometry to define the inner shoulder width.

Based on this concept, many researchers addressed their concerns in SSD provision for left-turn curved divided highways. For example Arndt [30] mentioned that the SSD adequacy process using the design criteria listed in the current design guidelines would lead to very wide shoulders, which was described as uneconomical, whereas in case of maintaining the original shoulder widths, rather conservative speed limit values should be implemented [31]. Therefore the adoption of the conventional approach, given by the current practice, besides the cost or performance impacts, may lead to road safety violation as well, since either the widened inner shoulder potentially can be used as an extra traffic lane for passing maneuvers especially by motorcyclists, or areas with unexpected speed discontinuity will emerge.

Klam et al. [32], aiming to improve available SSD in intersection areas, suggested the arrangement of shorter barriers (0.508 $\mathrm{m}$ high), referred to as low-profile barriers, in different locations in Texas and Florida, where merely the Test Level 2 criteria $(70 \mathrm{~km} / \mathrm{h})$ of the NCHRP Report 350 [33] were reached. As to increase the Test Level a stabilized rail was suggested to be attached to the low-profile barrier.

In another research [34], the risk evaluation of inadequate available SSD due to the presence of median barriers was examined via reliability analysis. A methodology was presented to calculate the probability of non-compliance that describes the associated risk of a driver requiring a sight distance greater than available in order to make a safe stop. However, since 2D approach instead of 3D assessment was utilized for the available sight distance, the accuracy of the results is uncertain.

Sarhan et al. [27] using previously developed software, examined the impact of roadside and median barriers on the available SSD on horizontal curves when overlapped with various vertical alignments. The results confirmed previous findings according to which the available sight distance depends on the type of the vertical alignment and the curvature of crest or sag vertical curves overlapping on the horizontal curve. The authors delivered charts, as an easy-to-use tool by designers, to estimate the available stopping sight distance on horizontal curves overlapped with a specific vertical alignment.

In AASHTO design guidelines, as far as divided highways are concerned, the recommended distance between the edge of the travelled way and the median barrier delivers available SSD values less than the relevant demanded, in order to safely lead a vehicle to a complete stop condition, before striking a sudden object [27].

Although the conventional SSD approach is adopted in the German RAA 2008 design guidelines as well, in situations of SSD shortage, it is recommended to modify the road alignment or decrease the speed limit. In every case SSD adequacy is advised to be assessed in 3D roadway environment, where no further instructions are provided [2].

Moreover, regarding curved sections where road safety barriers are involved, in terms of SSD adequacy assessment, it was found that through the conventional approach rather increased values of amended design parameters are delivered (e.g., increased inner shoulder widths) [29]. In these cases, less-conservative criteria for the parameters involved in the SSD adequacy process are introduced which are believed to be more realistic (ex. increased values of deceleration rate and obstacle height).

From the above it is evident that the 2D approach of SSD provision adopted in current design practice is inaccurate and at the same time closely associated to vehicle speed. The existence of a reliable tool to effectively and accurately perform SSD adequacy investigation on compound alignments (3D road environment) for a given speed value seems essential.

Moreover, none of the relevant research studies examined the impact of median barriers in SSD adequacy concurrently from the 3D alignment design viewpoint along with the vehicle kinematics. A critical issue to be examined through the present assessment is whether SSD adequacy on compound alignments and for a desired speed value can be achieved by retaining the original cross section shoulder widths. Therefore another objective of the paper is to define areas where the overlaid vertical design vertex on horizontal alignments generates SSD inadequacies and at the same time provide possible realistic solutions based on existing design parameter selection associated to SSD.

\section{3D SSD adequacy investigation for AASHTO 2011 design policy on left curved divided highways}

In order to investigate potential safety violation for AASHTO 2011 design guidelines, an example consisting of a left curved 
divided highway segment was examined. The utilized design parameters for the selected design speed of $130 \mathrm{~km} / \mathrm{h}$, at least from the vertical curvature point of view, seem rather comfortable as shown in Table 1. In the same Table the crucial design parameters accruing from the selected speed value $(130 \mathrm{~km} / \mathrm{h})$ are illustrated as well. It is clear that the speed value of $130 \mathrm{~km} / \mathrm{h}$ refers to the roadway's posted speed, where the road surface condition is assumed wet.

Since, according to AASHTO 2011, the maximum grade value for $130 \mathrm{~km} / \mathrm{h}$ assuming rolling terrain is set to $4 \%$, the crest vertical curve boundary grade values were set to -4 and $4 \%$ (symmetrical) respectively.

The examined cross section at the barrier area is shown in Fig. 3 and consists of a passing lane and an inner shoulder of 3.60 and $1.20 \mathrm{~m}$ respectively. The median barrier of Fig. 3 is "New Jersey" type with a height of $0.90 \mathrm{~m}(0.81 \mathrm{~m}$ plus safety margin), where its curvature at the top increases the inner shoulder by $0.22 \mathrm{~m}$ (Fig. 3).

As far as the driver's eye and object heights are concerned, 1.08 and $0.60 \mathrm{~m}$ were assumed (AASHTO 2011), where the deceleration rate and the driver's perception-reaction time were taken $3.40 \mathrm{~m} / \mathrm{sec}^{2}$ and $2.5 \mathrm{sec}$ respectively (AASHTO 2011). Finally, the lateral offsets of both driver and obstacle from the edge of the passing lane (Fig. 3) were assumed half of the lane width $(1.80 \mathrm{~m})$.

Figure 4 shows an example regarding SSD adequacy investigation on the $3 \mathrm{D}$ compound road surface formed by the above mentioned parameters ( $R=1000 \mathrm{~m}, K=200 \mathrm{~m}$, etc.). The horizontal axis represents the road stations where the horizontal and vertical curvatures are projected linearly (brown and magenta lines respectively), where it can be seen that the entire vertical transition falls inside the horizontal radius. The vertical axis illustrates various SSD values corresponding to the stations of the compound alignment shown horizontally. Three different types of SSDs are shown: $\mathrm{SSD}_{\text {DEMANDED }}$ (blue line), $\mathrm{SSD}_{\text {AVAILABLE (2D) }}$ (green line) based on roadway's longitudinal profile, and $\mathrm{SSD}_{\text {AVAILABLE }}$ (3D) (yellow line) based on 3D perspective analysis.

A closer look of Fig. 4 reveals an extensive underdesign zone, located at the area where the blue line ( $\left.\mathrm{SSD}_{\text {DEMANDED }}\right)$ is over the yellow one [SSD AVAILABLE $(3 \mathrm{D})$ ]. In terms of quantifying the SSD safety violation area between the

Table 1 Utilized and control design values in the SSD adequacy investigation $\left(\mathrm{V}_{\mathrm{d}}=130 \mathrm{~km} / \mathrm{h}\right)$

\begin{tabular}{lll}
\hline & Utilized value & Control value \\
\hline $\mathrm{R}(\mathrm{m})(e=6 \%)$ & 1000 & 950 \\
$\mathrm{~L}(\mathrm{~m})$ & 111 & 72 \\
$\mathrm{~K}(\mathrm{~m})$ & 200 & 124 \\
$\mathrm{~s}(\%)$ & 4 & 4
\end{tabular}

Legend: $R$ horizontal radius, $L$ spiral length (desirable, in AASHTO), $K$ rate of vertical curve, $s$ grade, $e$ superelevation rate
$\mathrm{SSD}_{\text {DEMANDED }}$ and the $\mathrm{SSD}_{\text {AVAILABLE }}(3 \mathrm{D})$, the total SSD breakdown zone, or in other words the partial road disappearance, is approximately $2472 \mathrm{~m}$ (area highlighted in cyan).

Commenting further on Fig. 4, it can be seen that AASHTO 2011 design guidelines fail to warrant safety during emergency braking of a vehicle moving with $130 \mathrm{~km} / \mathrm{h}$ on the passing lane of such a left curved divided highway, since the median barrier acts as a vertical wall between the object $(0.60 \mathrm{~m})$ and the driver $(1.08 \mathrm{~m})$ heights. This finding is not surprising since by applying basic geometric considerations, the barrier height $(0.90 \mathrm{~m})$ is greater than the average heights between the driver and the obstacle. Moreover, this assumption overestimates the actual available SSDs on curved horizontal sections overlapped with crest vertical curves [6].

In order to grant SSD adequacy, and at the same time retain the above height values, for the same vehicle speed, cross section and vertical profile, the horizontal radius value has to be increased to more than $3500 \mathrm{~m}$ approximately, which actually signifies SSD investigation from a solely horizontal alignment point of view.

Figure 4 represents only a single compound alignment case, where the vertical vertex is positioned at station 3200 . In order to investigate, in terms of SSD adequacy, the impact of the vertical alignment throughout the relevant horizontal alignment, a shift of the vertical vertex at fixed distances was performed in second level where a clear view of critical safety concerns is provided.

Figure 5 (upper part), illustrates SSD adequacy on the original horizontal alignment of which the same vertical parameters are drawn by positioning the vertical vertex every $200 \mathrm{~m}$. In other words between the range of St.1000-St.5400 of Fig. 5, the SSD adequacy investigation of 23 compound alignments of the same horizontal $(R=1000 \mathrm{~m})$ and vertical $(K=200 \mathrm{~m})$ geometry is delivered.

The horizontal axis of Fig. 5 illustrates the horizontal geometry, where the vertical quantifies the SSD shortage, since the difference between $\mathrm{SSD}_{\text {DEMANDED }}-\mathrm{SSD}_{\text {AVAILABLE }}$ is shown. In the same Figure (once again upper part), for $0.60 \mathrm{~m}$ object height, it can be seen that when the vertical vertex is placed on St.3200, where the starting and ending points of the vertical curve are at station 3200-800 and station $3200+800$ respectively, the length of road with SSD inadequacy, as already stated above is $2472 \mathrm{~m}$ approximately.

In current practice, as already stated, such cases are addressed by either decreasing the posted speed, or by defining the appropriate inner shoulder width in order to retain the initial speed.

Regarding the object height, it must be stressed that the German RAA 2008 design guidelines, in order to increase safety during night driving, determine the crest vertical curvature rate based on utilizing the tail lights as object height $(0.50 \mathrm{~m})$. However, in cases of SSD investigation where for example median barriers are present, in order for the driver to 
Fig. 3 Semi cross section view at the inner shoulder area

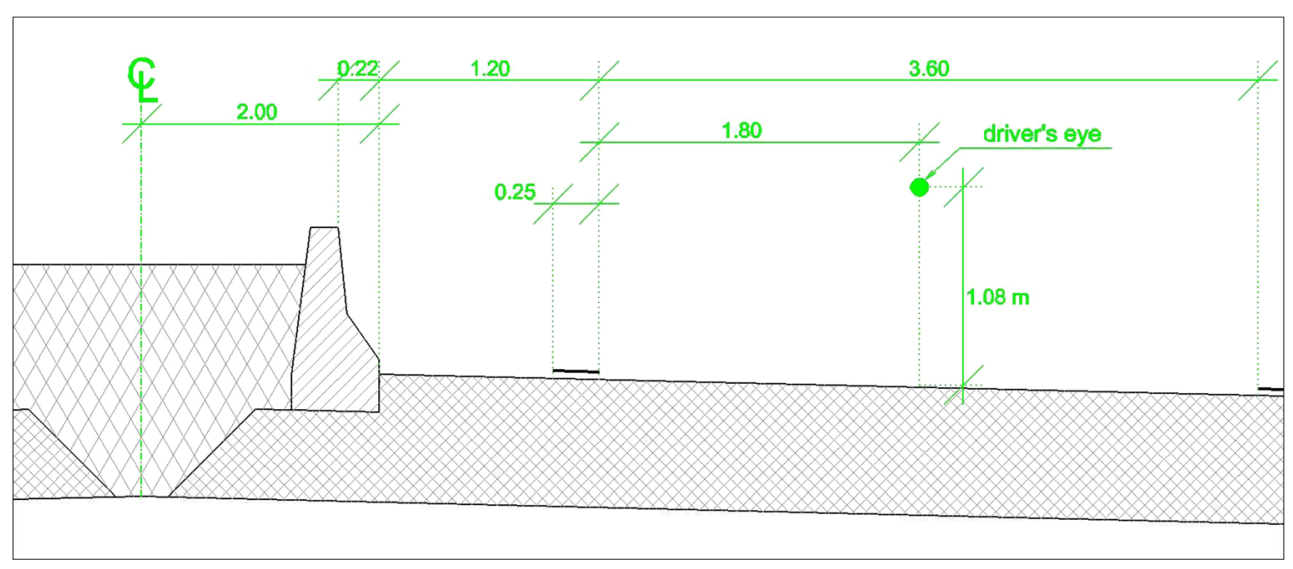

be able to identify a stopped vehicle, the object and driver's eye heights are equivalent $(1.00 \mathrm{~m})$.

The above concept is adopted at the bottom chart of Fig. 5, where by setting the object height equivalent to the driver's height $(1.08 \mathrm{~m})$, a massive improvement in terms of SSD adequacy is delivered. Examining more thoroughly the bottom area of Fig. 5, it can be seen that SSD provision adequacy is provided at the area where the crest vertical transition falls entirely inside the horizontal curve area, thus confirming, but even more expanding on divided roads, empirical recommendations addressed by current design guidelines [1, 4]. Moreover, a recent research by Moreno et al. [17] according to which the location of the vertical midpoint that maximizes available sight distance is located before the horizontal vertex, is validated on divided roads with median barriers as well.

The areas of peak SSD shortage in Fig. 5 are found at the entrance and exit areas of the horizontal curve where the vertical transition is about to end. For example at St.1600 the vertical transition concludes approximately $300 \mathrm{~m}$ inside the circular curve $(1600+800)$.

However, many of the above utilized parameters are either based on experience or do not represent the entire passenger vehicle fleet. Therefore, in order to point out -ready to use in practice- acceptable arrangements of compound alignments with adequate $\mathrm{SSD}$, even where the $\mathrm{SSD}_{\text {DEMANDED }}$ slightly exceeds $\mathrm{SSD}_{\text {AVAILABLE}}$, the authors introduce the term "tolerable road length not visible to the driver". This length represents the distance travelled during driver's perceptionreaction time, which is somehow forgiving since SSD inadequacy is implemented from this point ahead. Therefore, areas shown in Fig. 5 with SSD inadequacy up to $95 \mathrm{~m}$ approximately $\left(V=130 \mathrm{~km} / \mathrm{h}, \mathrm{t}_{\text {perc-reac }}=2.5 \mathrm{sec}\right)$ seem acceptable for positioning the vertical vertex.

The authors suggest that by increasing the object height to $1.08 \mathrm{~m}$ (equivalent to the driver's height), while performing SSD adequacy investigation on left curved divided highways, the consistency of the design as well as driver expectations can be satisfied in terms of avoiding ununiformed posted speed areas and unsuitable lateral road broadenings respectively, where in each case safety violations might occur as well.

Moreover, according to Federal Motor Vehicle Safety Standards [35], as the stop lamp heights of passenger cars fall between 38 and $183 \mathrm{~cm}$ (15-72inch), in order to avoid extensive design and operational interventions, it is a matter of enforcing the installation of additional stop lamps in passenger cars mounted not below $1.10 \mathrm{~m}$.

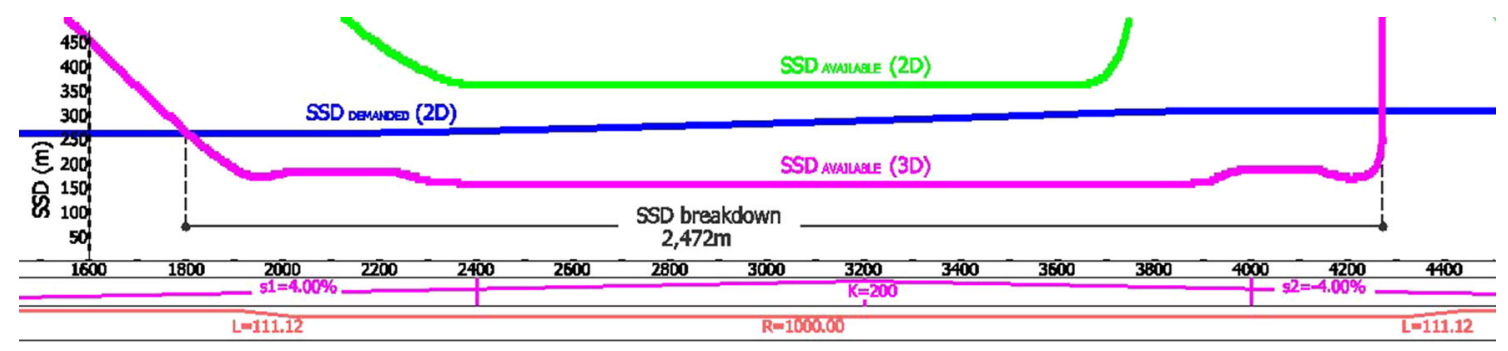

Legend: Vehicle Speed: $130 \mathrm{~km} / \mathrm{h}$

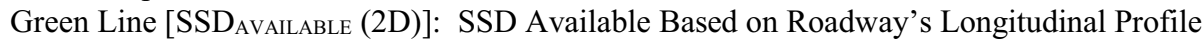

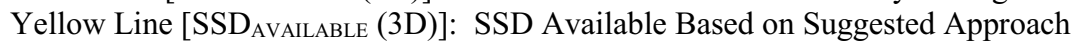

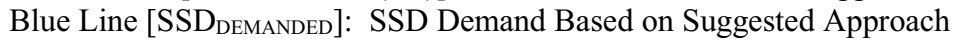

Vertical Vertex Station: 3200, Boundary of Vertical Transition Area: 3200-800, 3200+800

Fig. 4 SSD adequacy investigation on compound alignment $(R=1000 \mathrm{~m}, K=200 \mathrm{~m})$ 
Fig. 5 SSD adequacy investigation on left curved divided highway overlapped with crest vertical curve $(R=1000 \mathrm{~m}$, $K=200 \mathrm{~m})$

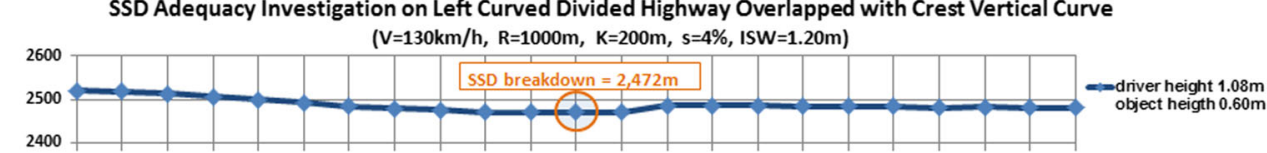

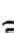

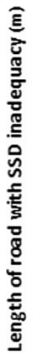
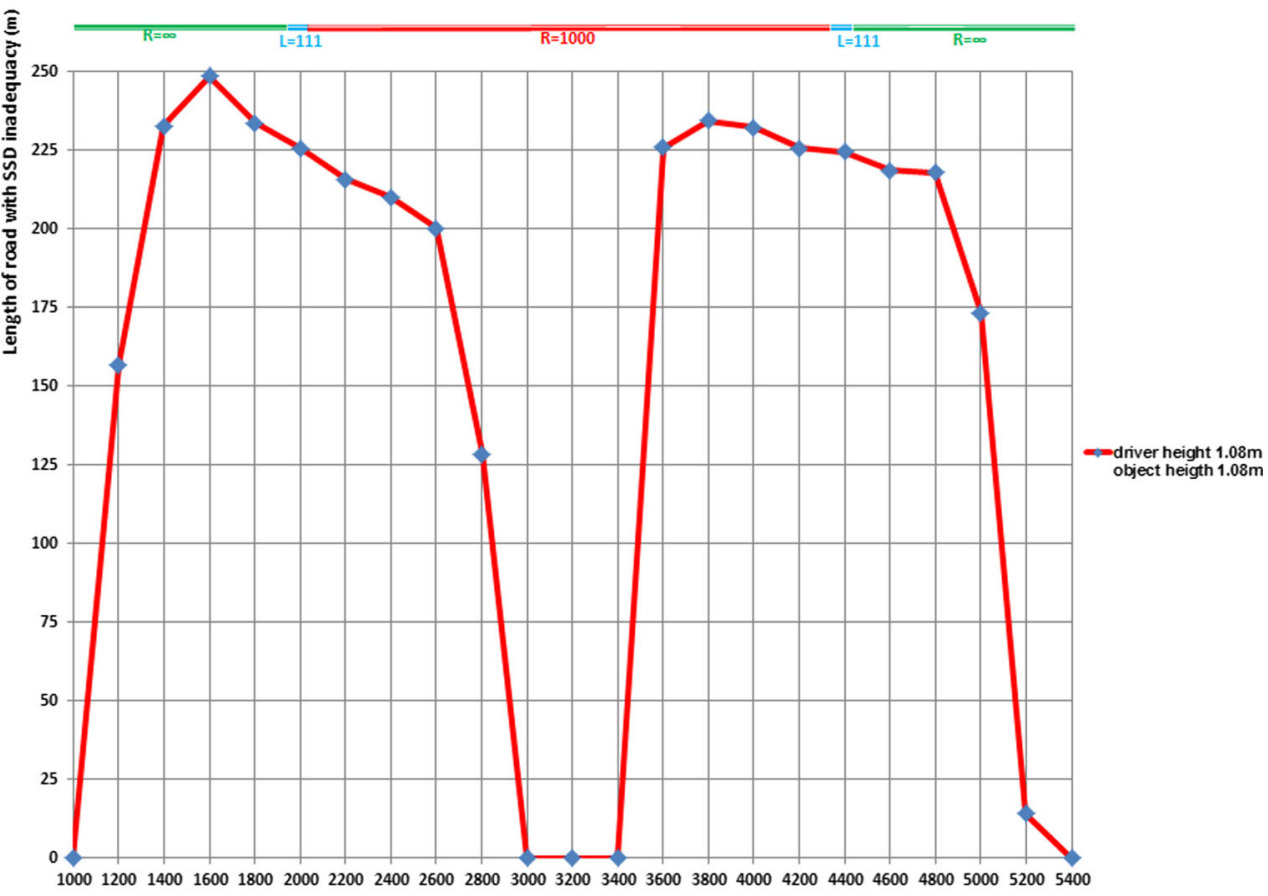

Horizontal Alignment $(\mathrm{m})$

Legend: Calculation Step $=200 \mathrm{~m}, \mathrm{~V}_{(\mathrm{km} / \mathrm{h})}$ : Vehicle Speed, $\mathrm{R}_{(\mathrm{m})}$ : Horizontal Radius, $\mathrm{K}_{(\mathrm{m})}$ : Vertical Curve Rate, $\mathbf{s}_{(\%)}$ :Absolute Boundary Grade Value of Vertical Curve, ISW $_{(\mathrm{m})}$ : Inner Shoulder Width

\section{Conclusions}

In this paper, the SSD adequacy investigation carried out on left-turn curved divided highways is based on the difference between the available and the demanded SSD. On the one hand, the $\mathrm{SSD}_{\text {DEMANDED }}$ is defined based on the point mass model introduced by many design guidelines worldwide, enriched by the actual values of grade and friction variation due to the effect of vertical curves and vehicle cornering respectively. On the other hand, the $\mathrm{SSD}_{\text {AVAILABLE }}$ is described as the driver's line of sight towards the object height at a certain offset in 3D roadway environment.

The paper is focused on examining potential safety violation for AASHTO 2011 design guidelines, regarding SSD provision for $130 \mathrm{~km} / \mathrm{h}$ vehicle speed, on the passing lane of left curved divided highway overlapped with crest vertical curves the alignment of which is rather comfortable.

Although a single case of compound alignment, in terms of design values utilization, was examined, the research revealed an extensive area of SSD inadequacy, where AASHTO 2011 design guidelines fail to guarantee safety during emergency vehicle braking. The impact of such cases can be detrimental to the cost and/or performance of existing and new road designs, since excessive geometry amendments (e.g., widening the inner shoulder or, as shown in the present paradigm, increasing the horizontal radius more than three times) and/or unnecessary posted speed areas seem inevitable, which may as well violate either the driver expectation or the design consistency respectively.

Therefore, in cases of SSD adequacy investigation on left curved divided highways, the authors suggest an increase of the object height to $1.08 \mathrm{~m}$, as the optimal mean to avoid extensive design and operational interventions.

It is accepted that it will not be feasible to retrofit the many millions of vehicles currently affected, but vehicle construction and use regulations should be modified to achieve this in the future vehicle fleet.

Further research is conducted at the moment to deliver a wide range of horizontal — vertical arrangements the positioning of which can be utilized in any order in order to grant SSD provision for such compound alignments.

Additional work is necessary as well in order to optimize, in terms of SSD provision, the influence of parameters involved, as for example the inner shoulder width, or the median barrier type for every utilized case (bridge or tunnel areas, interchange ramps etc.), where a more clear view of the safety margins will emerge. 
The parameters used in the present paper (speed values, perception of reaction time etc.) refer to daylight driving conditions, as, on the one hand, the vehicle speed values in night time driving conditions are $6-15 \mathrm{~km} / \mathrm{h}$ less [36] and on the other hand, the road view geometry changes.

Finally, it should not be ignored that, during the braking process, the human factor in terms of perception-reaction procedure might impose additional restrictions and, consequently, influence the braking process.

Open Access This article is distributed under the terms of the Creative Commons Attribution 4.0 International License (http:// creativecommons.org/licenses/by/4.0/), which permits unrestricted use, distribution, and reproduction in any medium, provided you give appropriate credit to the original author(s) and the source, provide a link to the Creative Commons license, and indicate if changes were made.

\section{References}

1. American Association of State Highway and Transportation Officials (AASHTO) (2011) A policy on geometric design of highways and streets, fifth edition. Washington, DC

2. (2008) Ed.German Road and Transportation Research Association, Committee, Geometric Design Standards. Guidelines for the Design of Roads, (RAA). Germany

3. Ministry of Environment, Regional Planning and Public Works (2001) Guidelines for the design of road projects, part 3, alignment (OMOE-X). Greece

4. Ministerio de Fomento (2000) Instrucción de Carreteras, Norma 3.1 - IC "Trazado". Spain

5. (2012) Ed.German road and transportation research association, committee, geometric design standards. Guidelines for the Design of Rural Roads, (RAL, R1). Germany

6. Hassan Y, Easa SM, Abd El Halim AO (1997) Design considerations for combined highway alignments. J Transp Eng 123(1):60 68

7. Sanchez E (1994) Three-dimensional analysis of sight distance on interchange connectors. In: Transportation Research Record 1445. TRB, National Research Council, Washington, D.C., pp 101-108

8. Hassan Y, Easa SM, Abd El Halim AO (1996) Analytical model for sight distance analysis on three-dimensional highway alignments. Transp Res Rec 1523

9. Lovell DJ, Jong JC, Chang PC (2001) Improvement to the sight distance algorithm. J Transp Eng 127(4):283-288

10. Nehate G, Rys M (2006) 3-D calculation of stopping-sight distance from GPS data. J Transp Eng 132(6):691-698

11. García A (2004) Optimal vertical alignment analysis for highway design — discussion. J Transp Eng 130(1):138

12. Zimmermann M (2005) Increased safety resulting from quantitative evaluation of sight distances and visibility conditions of two-lane rural roads. In: Proceedings of the $3 \mathrm{rd}$ International Symposium on Highway Geometric Design. TRB, Chicago

13. Ismail K, Sayed T (2007) New algorithm for calculating 3-D available sight distance. J Transp Eng 133(10):572-581

14. Romero MA, García A (2007) Optimal overlapping of horizontal and vertical curves maximizing sight distance by genetic algorithms. The 86th Annual Meeting of the Transportation Research Board. Washington, DC
15. Yan X, Radwan E, Zhang F, Parker JC (2008) Evaluation of dynamic passing sight distance problem using a finite - element model. J Transp Eng 134(6):225-235

16. DiVito M, Cantisani G (2010) D.I.T.S.: a software for sight distance verification and optical defectiveness recognition. In: Proceedings of the 4th International Symposium on Highway Geometric Design. TRB, Valencia

17. Moreno Chou A, Perez V, Garcia A, Rojas M (2010) Optimal 3-D coordination to maximize the available stopping sight distance in two-lane roads. In: Proceedings of the 4th International Symposium on Highway Geometric Design. TRB, Valencia

18. Kim D, Lovell D (2010) A procedure for 3-D sight distance evaluation using thin plate splines. In: Proceedings of the 4 th International Symposium on Highway Geometric Design. TRB, Valencia

19. Jha M, Kumar Karri GA, Kuhn W (2011) A new 3-dimensional highway design methodology for sight distance measurement. The 90th Annual Meeting of the Transportation Research Board. Washington, DC

20. Mertzanis F, Boutsakis A, Kaparakis I, Mavromatis S, Psarianos B (2013) Analytical method for three-dimensional stopping sight distance. Paper presented on the 3rd International Conference on Road Safety and Simulation. RSS2013, Rome, Italy

21. Mavromatis S., S. Palaskas and B. Psarianos. Continuous Three-Dimensional Stopping Sight Distance Control on Crest Vertical Curves. Paper published on the Advances in Transportation Studies (ATS), XXVIII issue, November 2012.

22. Krempel G (1965) Experimenteller Beitrag zu Untersuchungen an Kraftfahrzeugreifen. Dissertation. Karlsruhe

23. National Technical University of Athens (NTUA) (2012) H12, Road Design Software. NTUA, Greece

24. Mavromatis S, Pagounis V, Palaskas S, Maroudas D (2009) Stopping sight distance assessment via 3 -D road scanning. Paper presented and published on the 4th National Conference in Road Safety. Athens Greece, November

25. Leica Cyclone (2008) 3D point Cloud Processing Software, Leica Inc.

26. American Association of State Highway and Transportation Officials (AASHTO) (2006) Roadside design guide, Third Edition. Washington, D.C.

27. Sarhan M, Hassan Y () Consideration of Sight Distance in Placement of Road Concrete Barriers on Horizontal Curves. Presented at the 91st Annual Meeting of the Transportation Research Board. Washington, D.C., 2012.

28. Donnell E, Mason J (2006) Predicting the frequency of median barrier crashes on Pennsylvania interstate highways. Accid Anal Prev J 38(3)

29. Austroads (2009) Guide to road design series. Austroads, Australia

30. Arndt O, Cox R, Lennie S, Whitehead M (2010) Provision of sight distance around concrete barriers and structures on freeways and interchanges. In: Proceedings of the 4th International Symposium on Highway Geometric Design. TRB, Spain

31. Mavromatis S, Psarianos B, Kasapi E (2005) Computational determination of passenger cars' braking distances equipped with anti-block brake systems. In: Proceedings of the 3rd International Symposium on Highway Geometric Design. TRB, Chicago

32. Klam JW, DL Ivery (2010) Low-profile barrier with Tl-3 modification. Presented at 89th Annual Meeting of the Transportation Research Board, Washington, D.C. 
33. Ross HE Jr, Sicking DL, Zimmer RA, Michie JD (1993) Recommended procedures for the safety performance evaluation of highway features. NCHRP Report 350, Transportation Research Board, National Research Council. Washington DC

34. Richl L, Sayed T (2006) Evaluating the safety risk of narrow medians using reliability analysis. J Transp Eng 132(5):366-375
35. National Highway Traffic Safety Administration (NHTSA) (2011) Federal motor vehicle safety standards; lamps, reflective devices, and associated equipment. Washington, D.C.

36. Malakatas K (2012) Operating speed predicting model on two-lane rural roads during night-time. Diploma Thesis, National Technical University of Athens. Greece 